\title{
Actual Issues of Adaptation of Freshmen 2020: Challenges to Education
}

\author{
V.A. Ivashova \\ Consumer Expectations Monitoring Department \\ Stavropol State Agrarian University \\ Stavropol, Russia \\ vivashov@mail.ru
}

L.V. Volodkina

Department of Accounting

Russian State Agrarian University - Moscow Agricultural Academy named after K.A. Timiryazev

Moscow, Russia

volodkina@rgau-msha.ru

\author{
N.N. Shelemekh \\ Department of Taxation and Financial Law \\ Russian State Agrarian University - Moscow Agricultural \\ Academy named after K.A. Timiryazev \\ Moscow, Russia \\ nn996@mail.ru \\ O.N. Ivashova \\ Department of Information Technology in the AIC \\ Russian State Agrarian University - \\ MAA named after K.A. Timiryazev \\ Moscow, Russia \\ olga300377@yandex.ru
}

\author{
E.A. Yashkova \\ Department of Information Technology in the AIC \\ Russian State Agrarian University - \\ MAA named after K.A. Timiryazev \\ Moscow, Russia \\ ek_yashkova@mail.ru
}

\begin{abstract}
The article presents the research results of the adaptation of the modern generation of university freshmen to study. We present the analysis of the socio-psychological characteristics of the modern generation of freshmen 2020. New requests and expectations of students to the educational process at the university, the transformation of competencies demanded by the economy form development vectors for universities, including the issues of ensuring the successful adaptation of the new incoming students. We considered important trends in the discussion of adaptation problems that are described in the publications of the scientific community. The balance between socio-psychological and educational adaptation is justified when the university works with freshmen of 2020 . The key approaches in which may be as follows. The first is the development of an impression economy - a positive emotional background of what is happening. The second is a sense of importance and significance of the student's personality, psychological interaction. The third is creating a successful situation for everyone - a variety of proposals for finding areas of personal growth. The fourth is early immersion in social and professional networks. And the last is relevant educational and extracurricular digital content.
\end{abstract}

Keywords - socio-psychological adaptation, educational motivation, domestic adaptation, digital content

\section{INTRODUCTION}

Today, a generation that was born and matured along with the active development of digital technologies is coming to the universities. The expectations of freshmen 2020 do not always coincide with the proposals and characteristics of the educational process of universities, which at the stage of adaptation negatively affects educational motivation and the socio-psychological comfort of students. At the same time, the further attitude to academic work, interaction with teachers and peers depends on the successful development by students of the university system of requirements, norms and social relations, adaptation to a new system of education, and a mode of life activity.

\section{METHODS AND MATERIALS}

Pressing questions of adaptation of freshmen were studied by the example of students of Stavropol State Agrarian University via the Internet using the Google form.

The purpose of the study is to determine the level of adaptation of freshmen to university education.

In total, 659 people took part in the survey, which makes up $80.6 \%$ of freshmen at the full-time, undergraduate and specialty levels.

Adaptation was seen as a process of entering student life.

The study gives a characteristic of the educational and socio-psychological adaptation of first-year students of all faculties, a description of the socio-demographic portrait of freshmen, the needs for additional professional education. 


\section{RESULTS}

\section{A. Socio-demographic portrait of freshmen}

The majority of freshmen are from complete families (noted by $72.1 \%$ ), in which relations based on mutual understanding and support $(66.2 \%)$ are formed and only sometimes disagreements arise (noted by 25.5\%). A small percentage of students $-3.3 \%$, who noted that family relationships are complex and there are serious differences are at risk.

The financial situation of families is estimated by half of first-year students as average. The same amount $-13.5 \%$ indicated that they live slightly better than the average people around and live a little worse than others. A small proportion $7.8 \%$ of freshmen believe that the material well-being of their families is much higher than the average standard of living in the region. $1.5 \%$ of students believe that the material wellbeing of their families is very low. $10.3 \%$ of the survey participants were not able to give a certain assessment.

About a third of freshmen live with their parents or relatives, a third live in a dormitory and a third rent an apartment or live in their own apartment.

Most students came to the regional center to study from other settlements and have a small budget for a month: a quarter of the students cost up to 6.0 thousand rubles a month; about $17 \%$ indicated a budget from 6.0 thousand rubles to 8.0 thousand rubles; about $17 \%$ indicated a budget of over 8.0 thousand rubles.

Only half of the students rate their health as "good." Another third of the students rate their health as "satisfactory". At risk for possible missed classes and lagging in the schedule of mastering academic disciplines are $12.6 \%$ of first-year students who said that their health was poor. It is difficult to give a certain assessment of the state of health of $5.3 \%$ of survey participants.

\section{B. Socio-psychological adaptation of freshmen}

The provision of educational services is associated with certain emotions and impressions. Considering that the educational process is a laborious mental activity, if the emotional mood and impressions of the lessons turn out to be positive, the student has additional educational motivation. Creating a situation of success in certain types of educational, research and extracurricular activities allow you to unleash the potential of the student in the process of learning at the university, and in this regard, the initial stage of training and successful adaptation to it play an important role.

A large educational work was carried out at all faculties with freshmen, including attraction for participation in major university events: "Youth Leader", "Freshman Cup", and "Young Talents".

For the period from September to December 2019, the results that confirm the successful social and professional adaptation are the following:

$-72.6 \%$ of the survey participants indicated that they liked the study group, $21.1 \%$ said they liked it rather than not. A very small proportion of first-year students indicated that they did not like the study group $-2.1 \%$ of the survey participants. The study group does not quite like another $21.1 \%$ of the survey participants. Difficult to give a certain assessment of their attitude towards the group of $3.2 \%$ of freshmen;

$-87.5 \%$ of freshmen in study groups made friends;

$-67.3 \%$ of the number of survey participants are satisfied with the psychological microclimate that has developed in the study groups and another $26.1 \%$ are more likely satisfied than not;

- high satisfaction with relations with teachers is also noted $-87.7 \%$ of first-year students positively assess this aspect of socio-psychological adaptation;

$-95.9 \%$ of first-year students indicated the presence of a study group curator in their student life. $85.8 \%$ of the survey participants noted that it was the curator who helped them to get used to at the first stages of training. $74.7 \%$ turned to the curator with any questions of study and life;

- $95.9 \%$ of survey participants said they are informed about the activities of student associations and $67.3 \%$ are already taking part in their work;

- about $80 \%$ of freshmen take an active part in the activities of both the course and the study group.

Among the problem areas of socio-psychological and everyday adaptation of freshmen are nutrition issues. Only $20.5 \%$ of freshmen eat at the University's catering facilities On average, on a ten-point scale, freshmen are rated at 7.8 points, which is a rather low indicator. The problem of the significant time spent by students on the Internet remains a problem: $51.4 \%$ of survey participants spend 2 to 6 hours a day on the Internet and $23.2 \%$ spend more than 6 hours. About $60 \%$ of freshmen are present in virtual contacts in three or more networks.

\section{Freshman learning adaptation}

The ranking of the significance of factors that had an impact on the choice of a university by freshmen showed the following results:

1st place - the desire to master the profession in which training is carried out in high school $(52.1 \%$ of the survey participants noted);

2nd place - high quality teaching, which they learned from relatives and friends ( $41.8 \%$ of the survey participants noted);

3rd place - interesting student life $(38.1 \%$ of the survey participants noted);

4th place - the possibility of employment after graduation (37.3\% of the survey participants noted);

5 th place - state status of the university $(35.7 \%$ of the survey participants noted);

6th place - fame and prestige of the university (30.3\% of the survey participants noted).

It should be noted that freshmen made a choice in favor of factors socially and professionally significant for their future 
professional careers. At the same time, factors emphasizing the lack of choice, lack of professional goals, gained an insignificant place in the responses of the survey participants: low competition in the direction of preparation in which they study (5\% of the survey participants noted). The decision was made by their parents, the choice of friends, classmates according to the principle "Where everything is there and I go!" (2.6\% of the survey participants noted); there was no other choice ( $4.1 \%$ of the survey participants noted).

In general, we can conclude that at the stage of choosing a university and educational program, freshmen have a high educational motivation.

$76.5 \%$ of freshmen are well aware of the specialty in which they are studying. Only $3.3 \%$ of the survey participants have no idea about future professional activities.

High awareness of future professional activities is also a positive factor in maintaining the educational motivation of freshmen. Almost half of the freshmen spoke about positive changes in their attitude to the chosen profession. Another $36.1 \%$ of freshmen noted that the attitude has not changed. The changes for the worse were expressed in the survey by $5.2 \%$ of the number of freshmen who participated in the survey.

Only half of the freshmen confidently said that they did not have trouble at the stage of entering student life. $40 \%$ of freshmen had some difficulties. And every tenth noted that there are still problems of adaptation.

$14.3 \%$ of freshmen can easily cope with the training load. $24.7 \%$ thought it would be easier, but school knowledge was not enough to successfully master the content of the courses without additional training. $29.4 \%$ of freshmen said that it was difficult for them due to the large volumes of preparation for training sessions. $26.6 \%$ of the number of respondents noted that there are difficulties due to ordinary laziness, but they are working on themselves. Risk group $-5 \%$ of freshmen who said they could not cope with the workload.

The instrumental mechanisms of the educational process that have been proposed by universities have improved the process of adaptation of freshmen.

There are a number of conditions that helped freshmen to adapt to the learning process:

- cooperation in the group $(35.5 \%$ of the survey participants noted);

- desire to learn (25.7\% of the survey participants noted);

- friendly attitude of teachers $(15.3 \%$ of the survey participants noted);

- school habit of studying (12.2\% of the survey participants noted);

- curator's advice and assistance $(11.3 \%$ of the survey participants noted).

Difficulties in teaching freshmen are associated, first of all, with a low level of school preparation (noted by $21.3 \%$ of the survey participants); insufficient motivation for learning (noted by $14.2 \%$ of the survey participants); unwillingness to spend time preparing for training sessions (noted by $13.3 \%$ of survey participants).

For the generation of modern freshmen, the digital content of all processes plays an important role in everyday, including educational, practice. Almost all freshmen are familiar with the electronic resources of the university: timetable, electronic library, personal account of the student and teacher. At the same time, there are significant problems in the work of students' personal accounts: $42.5 \%$ do not enter them, because they do not remember the password. Thus, from the first year, almost half of the students have poorly formed culture and work skills in the students' personal cabin.

At the same time, such a digital communication tool as a presence on social networks to use operational information about current events at a university is used widely. $70.6 \%$ of freshman survey participants use social networks all the time, $22.4 \%$ use it occasionally, $3.5 \%$ have their own group in social networks. Only $3.5 \%$ of freshmen do not use social networks in solving information and communication issues.

Thus, we can only talk about a satisfactory level of educational adaptation of freshmen.

The expectations of freshmen - the generation that was born and matured with the active development of digital technologies, do not always coincide with the proposals of the educational process.

In this regard, extra-curricular work at the university is more adapted to the modern ideas of youth about cultural and leisure activities, art, education of citizenship and patriotism, tolerance and humanism.

\section{DISCUSSION}

The topics of students' adaptation to educational activities, the characteristics of the young generation and the related challenges for educational systems have received wide scientific discussion in the global scientific community.

For the modern generation of young people, the situation of inclusion in such an area of deviant behavior as gambling is widespread. In this regard, young people with problematic gambling behavior are subject to serious academic, behavioral and mental consequences, including educational setbacks [1]. The authors of the Enhancing the Relevance and Effectiveness of a Youth Gambling Prevention Program for Urban, Minority Youth: A Pilot Study of Maryland Smart Choices study concluded that special corrective programs are needed. Such programs should reflect the specific goals of involving students in educational projects and promoting positive behavior. In general, the implementation of programs will help reduce the deviation associated with the gaming disorder of the younger generation [2]

Liu H.-Y., Chao C.-Y., Kain V.J., Sung S.-C. [3] noted the importance of extracurricular work during vocational training at a college. Due to the wide involvement of students in extracurricular activities, they gain important competencies for successful professional adaptation at the workplace. 
Extracurricular work gives the development of personal and leadership skills [4].

Scientists Elliot D.L., Kobayashi S. on the basis of a qualitative study examine the experience of academic leaders and foreign graduate students regarding academic and psychosocial adaptation in a new cultural environment and emphasize the importance of intercultural aspects of mentoring of academic leaders [5]. This emphasizes the importance of curatorial service, mentoring and ensuring constructive intercultural communications and tolerance, especially during the period of adaptation of students and graduate students to study at a university $[6,7,8,9,10,11,12$, $13]$.

Authors Shipunova O.D., Berezovskaya I.P., Smolskaia N.B. highlight the problem of psychological adaptation of students to the electronic expansion of the learning environment. The authors connect the adaptive abilities of students with the nature of motivation for learning and the level of personal development in the process of acquiring new knowledge. The unity of the vectors of individual development in this regard correlates with the matrix of selfrealization, which characterizes the integral structure of the personality and the speed of development of its abilities in the learning process $[14,15]$.

The results of a quantitative study conducted by the authors Selimović A., Selimović L.T., Emić, E., Husarić M. in college based on a representative sample of students showed the adaptation process depending on the self-esteem of the survey participants. College adaptation is structured as emotional, social, academic, and institutional [16, 17, 18].

Practical training and inclusion in innovations are defined by scientists Cascón-Pereira R., Moral Martín J.D., Brunet Icart I. as a necessary competency that students must develop in order to improve their skills to adapt to future production tasks [19]. Early involvement in professional contacts and the solution of practical production functions, expansion of students' social and professional communications positively affects the adaptation process in an educational organization $[20,21]$.

Thus, the current scientific discussion confirms the relevance of the research presented in the publication and the new approaches of educational organizations to improving the process of adaptation of the first-year students of generation 2020 to study at a university

\section{CONCLUSION}

The results of the study allow us to draw a number of conclusions regarding changes in the adaptation process of modern freshmen 2020:

- the widespread use of tools of the economy of impressions (involvement in a large number of mass events, the possibility of developing creative abilities, personal growth) gives positive results in the development of students' communicative abilities, teamwork skills, and taking responsibility for decision-making;
- there is a direct positive correlation between the quality of educational work at the university and the level of sociopsychological adaptation of freshmen to study;

- effective tools for educational adaptation are: creating a situation of success for everyone through a variety of proposals for finding areas of personal growth; early immersion in social and professional networks; relevant educational and extracurricular digital content.

The information obtained during the study of the adaptation process for students of generation 2020 can be useful for finding new approaches to working with freshmen at the stage of entering university reality for successful development of status-role features of behavior, immersion in social and professional relations, characteristic of future professional activity.

\section{References}

[1] B.R. Parham, C. Robertson, N. Lever, K. Willis, J. Prout, "Enhancing the Relevance and Effectiveness of a Youth Gambling Prevention Program for Urban," Journal of Gambling Studies, vol. 35(4), pp. 12491267, 2019.

[2] F. Ishkineeva, K. Ozerova, S. Ahmetova, A. Kaveeva, "Students healthy lifestyle and the strategy of adaptation to the university environment," International Journal of Innovative Technology and Exploring Engineering, vol. 9(1), pp. 5123-5126, 2019

[3] H.-Y. Liu, C.-Y. Chao, V.J. Kain, S.-C. Sung, "The relationship of personal competencies, social adaptation, and job adaptation on job satisfaction," Nurse Education Today, vol. 83,pp. 104-199, 2019.

[4] F.Z. Colak, L. Van Praag, I. Nicaise, "A qualitative study of how exclusion processes shape friendship development among TurkishBelgian university students," International Journal of Intercultural Relations, vol. 73, pp. 1-10, 2019.

[5] D.L. Elliot, S. Kobayashi, "How can $\mathrm{PhD}$ supervisors play a role in bridging academic cultures?," Teaching in Higher Education, vol. 24(8), pp. 911-929, 2019.

[6] H. Güzel, S. Glazer, "Demographic correlates of acculturation and sociocultural adaptation: Comparing international and domestic students," Journal of International Students, vol. 9(4), pp. 1074-1094, 2019.

[7] J. Li, X. Gu, Z. Zhan, Y. Tan, S.R. Fussell, "New to the US: Understanding the role of CMC in international students' adaptation to the US," Proceedings of the ACM Conference on Computer Supported Cooperative Work, CSCW pp. 283-287, 2019.

[8] L. Regan, L.R. Hopson, M.A. Gisondi, J. Branzetti, "Learning to learn: A qualitative study to uncover strategies used by Master Adaptive Learners in the planning of learning," Medical Teacher, vol. 41(11), pp. 1252-1262, 2019.

[9] N. Gopalan, N.J. Beutell, W. Middlemiss, "International students academic satisfaction and turnover intentions: Testing a model of arrival, adjustment, and adaptation variables," Quality Assurance in Education, vol. 27(4), pp. 533-548, 2019

[10] C.M.H. Garre, M.M.F. Martínez, J.J.C. Martínez, B.A. Soler, "Socioeducational inclusion in the university of minho. Perceptions and attitudes about students with disabilities," Revista Complutense de Educacion, vol. 30(4), pp. 1097-1112, 2019.

[11] A. Binhas, L. Yaknich, "You have to start from scratch and you need someone by your side: Perspectives of parents and teachers on immigrant students' adaptation to school," International Migration, vol. 57(5), pp. 252-270, 2019.

[12] T. Hirota, M. Adachi, M. Takahashi, K. Nakamura, "Cross-cultural adaptation and psychometric properties of the Social Capital Questionnaire for Adolescent Students among preadolescents and adolescents in Japan," Psychiatry and Clinical Neurosciences, vol. 73(9), pp. 601-602, 2019. 
[13] A. Yüksel, E. Bahadır-Yılmaz, "The effect of mentoring program on adjustment to university and ways of coping with stress in nursing students: A quasi-experimental study," Nurse Education Today, vol. 80, pp. 52-58, 2019.

[14] O.D. Shipunova, I.P. Berezovskaya, N.B. Smolskaia, "The role of student's self-actualization in adapting to the e-learning environment," ACM International Conference Proceeding Series pp. 745-750, 2019.

[15] T. Jagušt, I. Botički, "Mobile learning system for enabling collaborative and adaptive pedagogies with modular digital learning contents," Journal of Computers in Education, vol. 6(3), pp. 335-362, 2019.

[16] A. Selimović, L.T. Selimović, E. Emić, M. Husarić, "Self-esteem and adaptation to college: Do students of higher self-esteem have a better emotional, social and academic adaptation?," Primenjena Psihologija, vol. 12(3), pp. 263-281, 2019.

[17] F. Valieva, J. Sagimbayeva, D. Kurmanayeva, G. Tazhitova, "The sociolinguistic adaptation of migrants: The case of Oralman students' studying in Kazakhstan,” Education Sciences, vol. 9(3), P.164, 2019.
[18] T. Gonçalves, M.S. Lemos, C. Canário, "Adaptation and validation of a measure of students' adaptive and maladaptive ways of coping with academic problems," Journal of Psychoeducational Assessment, vol. 37(6), pp. 782-796, 2019.

[19] R. Cascón-Pereira, J.D. Moral Martín, I. Brunet Icart, “An exploration of the meanings of innovation held by students, teachers and SMEs in Spain," Journal of Vocational Education and Training, vol. 71(4), pp. 623-644, 2019.

[20] F. Seyitoğlu, “Gastronomy students' internship experience: benefits, challenges, and future career," Journal of Teaching in Travel and Tourism, vol. 19(4), pp. 285-301, 2019.

[21] V.N. Grechukha, M.Y. Berezin, S.S. Bochkova, T.Y. Kochepasova, L.I Ovchinnikov, D.V. Shepeleva, N.N. Shelemekh, V.V. Mizyureva, "Correction of student personality moral culture: universals of interdisciplinary modules," Modern Journal of Language Teaching Method, vol. 8 (3), pp. 337-338, 2019. 